Volker Hockmann | Heinz-Dieter Knöll

\title{
Profikurs \\ Sicherheit von \\ Web-Servern
}

Ein praxisorientiertes Handbuch - Grundlagen, Aufbau und Architektur - Schwachstellen und Hintertüren - Konkrete Praxisbeispiele realisiert unter Windows und Unix/Linux

Mit 27 Abbildungen

PRAXIS

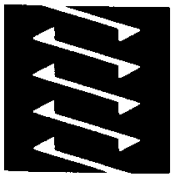




\section{Inhaltsverzeichnis}

1 Ziel dieses Buches

2 "Wir sind sicher - Wir haben eine Firewall

3 Allgemeines zu Web-Servern ..........................................................

4 Protokolle, Datenverkehr und Logfiles ............................................... 11

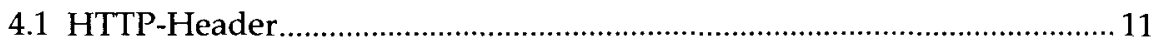

4.2 Protokolldateien des Microsoft Internet Information Services .................... 13

4.3 Protokolldateien des Apache-Servers........................................................... 14

4.4 Wie funktioniert ein Web-Server.............................................................. 16

5 Zugriffsmethoden (Request Methods) …………………..................... 19

5.1 GET-Methode

5.2 HEAD-Methode

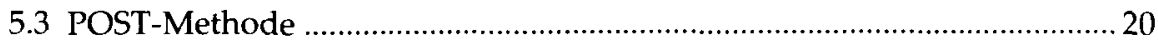

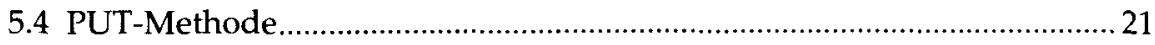

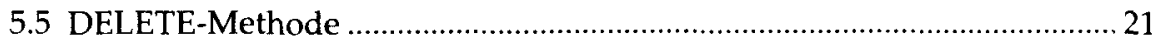

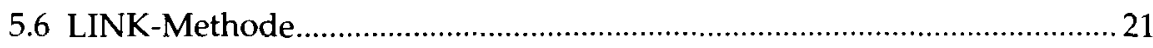

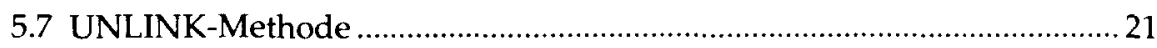

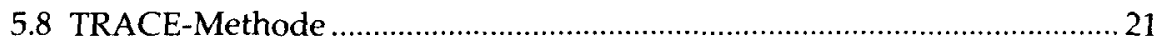

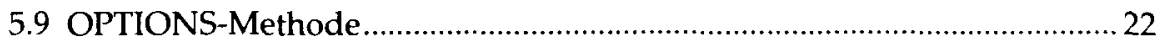

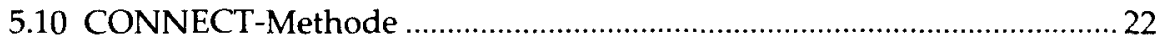

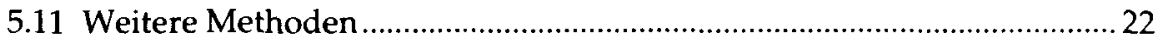




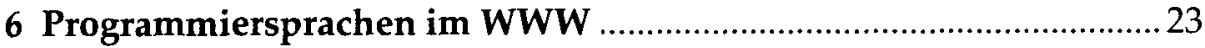

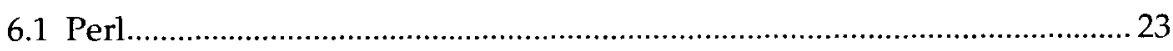

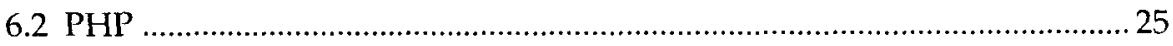

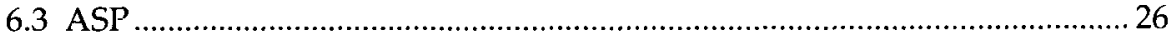

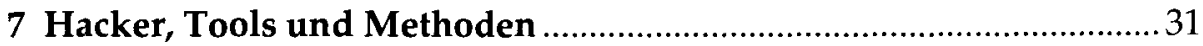

7.1 Abgrenzung: Hacker, Cracker, Angreifer ................................................. 31

7.2 Typen und Klassifizierungen von Angriffsmethoden .............................. 34

7.3 Scanner, Sniffer, Passwortknacker und weitere Tools aus dem Internet... 35

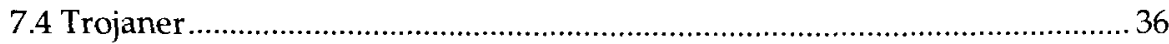

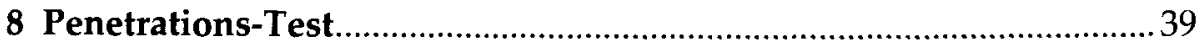

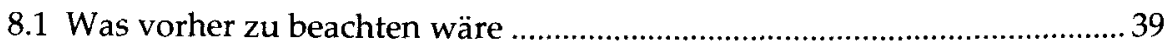

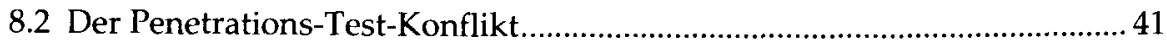

9 Informationsbeschaffung anhand eines Beispiels .........................45

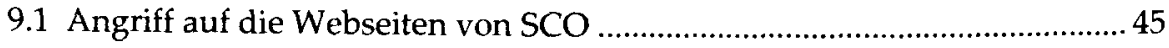

9.2 Informationsbeschaffung mittels Suchmaschinen am Beispiel Google .... 48

9.2.1 Informationsbeschaffung Microsoft IIS 6.0 .................................. 48

9.2.2 Google Suchanfragen nach verschiedenen Arten und Standardseiten von Web-Servern ................................................. 50

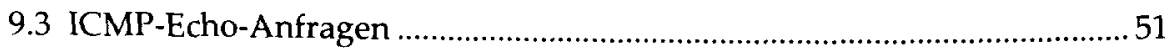

9.4 Informationen über Netzwerke sammeln ................................................... 51

9.4.1 Dateistrukturen auf Ihrem Server auflisten nach Eingabe einer

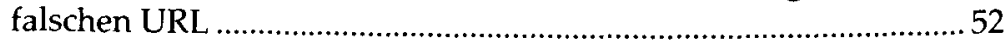

9.4.2 Informationen zu Applikationen sammeln...................................52

9.4.3 Informationen über angelegte Ordner, Dateien auf dem

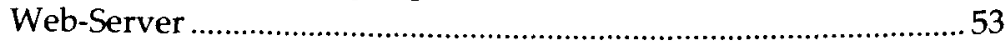

9.4.4 Stand der installierten Updates und Patches auf dem Server ....... 55

9.4.5 "Out of Office"-Nachrichten per Email........................................... 55 


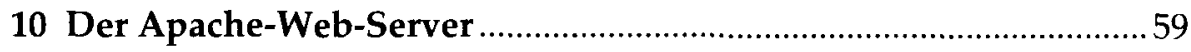

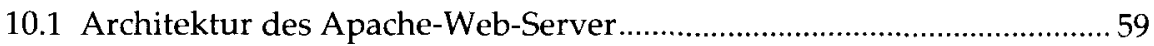

10.2 Multi-Thread und Multi-Prozess Web-Server............................................. 61

10.3 Serverlogging und Status beim Apache-Server …………........................61

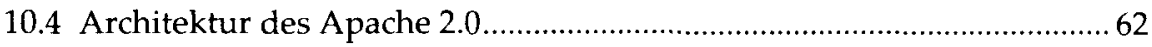

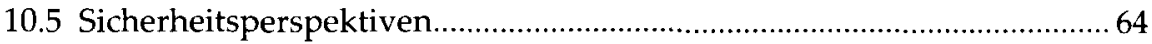

10.5.1 Installation des Apache unter einem anderen Benutzer ............... 64

10.5.2 Dateisystem des Web-Server absichern..........................................65

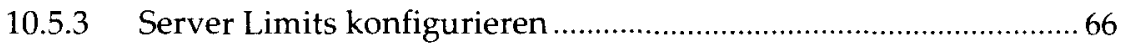

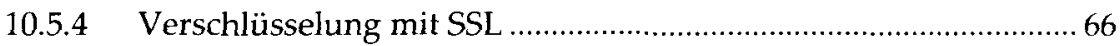

10.5.5 Zugriffsbeschränkungen per .htaccess .........................................67

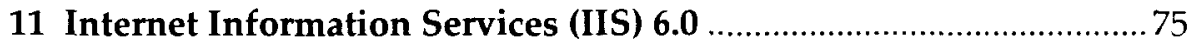

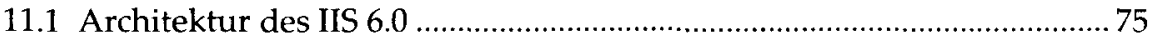

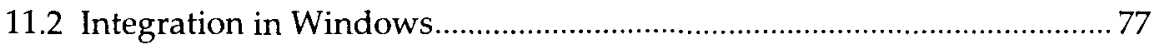

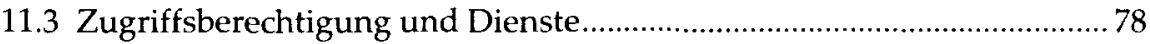

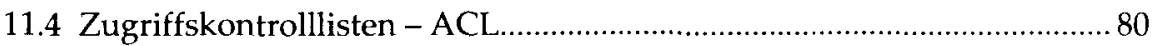

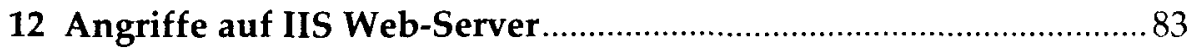

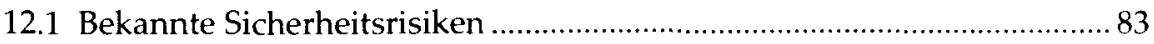

12.1.1 Lockout-Funktion auf einem Web-Server ..................................... 88

12.1.2 RPC-DCOM-Verwundbarkeiten ................................................... 89

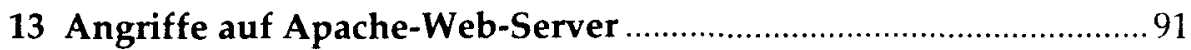

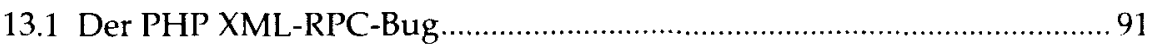

13.2 Pufferüberlauf im Apache Tomcat Connector ……................................ 92

13.3 Der Angriff auf die Software Foundation Web-Server ........................... 92 


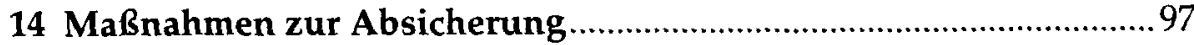

14.1 Grundlegende Maßsnahmen ................................................................... 98

14.1.1 Updates installierter Systeme und Programme ............................. 98

14.1.2 Entfernung aller unnötigen Script-Mappings und

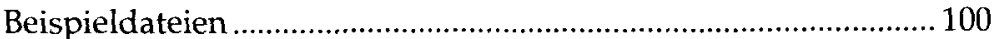

14.1.3 Zugriffsrechte für die Verzeichnisse festlegen ............................. 101

14.1.4 Den IIS-Dienst als separaten Dienst laufen lassen ....................... 102

14.1.5 Härten des Betriebssystems ............................................................ 103

14.1.6 Konzepte und Vorüberlegungen zur Absicherung ...................... 113

14.1.7 Tools und Programme zur Absicherung des Apache-Servers.... 113

14.1.8 Tools für den Internet Information Service ................................... 118

14.1.9 Tools für Apache (Windows/Unix) ........................................... 120

\section{5 „Wenn es doch passiert ist" - Was ist nach einem Einbruch zu} tun?

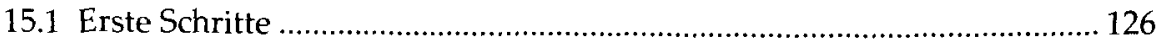

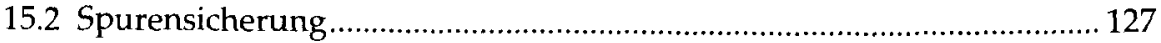

15.3 Rechtliche Aspekte der Forensik ....................................................... 128

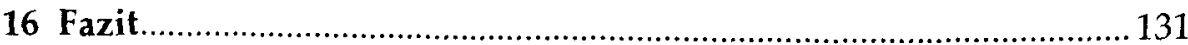

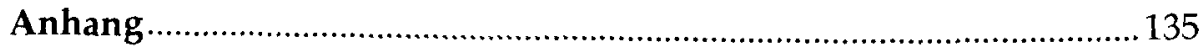

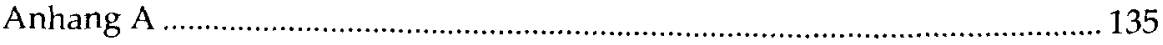

Anhang B - Apache Response Codes............................................................ 137

Anhang C - IIS Response Codes ................................................................. 139

Anhang D - Beispielcode bindshell.c ............................................................. 143

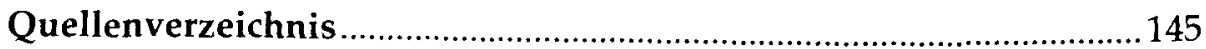

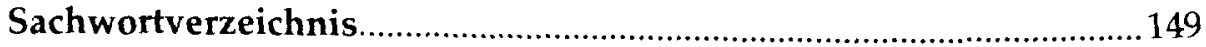

